\title{
Correlation between Vascular Endothelial Cell Growth Factor (VEGF) and Muscular Ultrasonography Finding in Knee Osteoarthritis
}

Mayada Khalil a , Mounir Serag Eldeen ${ }^{\text {a }}$, Samy E. Egela a , Yasmine Hadhoud ${ }^{\text {a }}$, Al-Shaimaa M. Al Tabbakh ${ }^{\mathrm{b}}$

\footnotetext{
${ }^{a}$ Department of Rheumatology , Rehabilitation and physical medicine, Benha faculty of medicine , Benha University, Egypt. $\quad \mathrm{b}$ Department of Medical Microbiology and Immunology department, Benha Faculty of medicine, Benha University, Egypt.
}

Correspondence to: Yasmine Hadhoud, Department of Rheumatology, Rehabilitation and physical medicine, Benha faculty of medicine, Benha University, Egypt.

Email:

jasmine.mohy@gmail.com

Received: 29 October 2020

Accepted: 11 November 2020

\begin{abstract}
:
Background: Osteoarthritis (OA) is a degenerative joint disorder affecting articular cartilage that may be associated with synovial inflammation. The vascular endothelial growth factor is implicated in the pathogenesis of OA. This study aimed to assess man serum vascular endothelial growth factor (VEGF) levels in patients with primary knee osteoarthritis (KOA) and to evaluate their correlation with clinical manifestations, physical function and musculoskeletal-ultrasonography findings. Results: This is a case control study conducted on 50 subjects, thirty patients with primary Knee OA recruited from the outpatients' clinic of the Rheumatology, Rehabilitation and Physical Medicine Department Benha University Hospitals, from November 2018 to November 2019. Twenty age and sex matched apparently healthy adult individuals were also included as a control group. The present study showed a highly statically significant difference $(p<0.0001)$ between
\end{abstract} the mean serum levels of VEGF in the patients' and the control groups being higher in the patients group compared to the control group $(<\mathbf{0 . 0 0 1})$. The current study revealed a strong significant positive correlations of VEGF levels with the presence of Baker's cysts, cartilage thickness index and color Doppler US grading $(\mathbf{p}<\mathbf{0 . 0 0 0 1})$. Significant positive correlations were also reported between VEGA levels $(\mathrm{p}=<0.001)$ and WOMAC total and WOMAC sub scores. 
Conclusions: VEGF serum levels are highly correlated with clinical, functional and musculoskeletal ultrasound severity of KOA. Thus it could be used as a potential biomarker for estimating Knee OA disease status

Key words: Knee OA, WOMAC, VEGF, Musculoskeletal Ultrasound

\section{Introduction}

Osteoarthritis (OA) is a degenerative articular disorder affecting about $40 \%$ of the old age population [1]. The core clinical features of $\mathrm{OA}$ are joint pain and swelling that strongly distress the patients' activities of daily living [2]. So, treatments are directed towards pain control or knee joint replacement [3]. OA pathology is complex as it leads to subchondral bone remodeling, osteophyte formation, articular cartilage degeneration and synovial inflammation [4]. Late OA synovitis exacerbates structural damage, chondrocyte function changes, aggressive angiogenesis and increased bone turnover [5].

Angiogenesis is characterized by the development of new capillaries from the preexisting vasculature which is important in pannus formation and destruction during progression of RA [6]. Both angiogenesis and inflammation are closely integrated in the pathogenesis of OA up-setting disease advancement [7]. Macrophage cells are abundantly present in the inflamed synovium of diseased joints and so are implicated in this process as secreting inflammatory mediators like vascular endothelial growth factor (VEGF) that is one of the key factors encouraging growth of blood vessels [8]. Hypoxia in particular markedly affects VEGF titers, activity in the way that induces new blood vessel growth [9]. VEGF acts through a series of tyrosine kinase receptors including VEGFR1，2, and 3 [10]. VEGFA is expressed by healthy cartilage while its great expression is concerned with OA severity [11]. In OA increased endothelial cell divisions and angiogenesis were followed by rapid vascular retraction resulting in minimal increase of vascular bulk $[12,13]$.

In the recent decades, imaging modalities including magnetic resonance imaging (MRI) and Doppler Ultrasound (US) are widely used as 
good substitutes for the diagnosis of joint abnormalities [2]. For example, ultrasound allows clear and subtle evaluation of synovial membrane pathology causing grey scale features like (effusion, synovial hypertrophy and bursitis). Furthermore, Power Doppler signals (PDS) increase within OA joint synovium denoting more inflammation [14].

\section{Aim of the Work:}

The aim of the present study is to measure serum VEGF levels in primary knee OA patients and to evaluate its correlation with clinical features, physical function and musculoskeletal ultrasound findings of this disease.

\section{Methods:}

\section{Study participants:}

This is a case control study conducted on 50 subjects, thirty patients with primary Knee OA recruited from the outpatients' clinic of the Rheumatology , Rehabilitation and Physical medicine department of Benha University Hospitals, from November 2018 to November 2019. Twenty age and sex matched apparently healthy adult individuals were also included as a control group. Our cases fulfilled the American College of Rheumatology (ACR) criteria for primary KOA [15]. Patients with a past history of knee surgery, secondary KOA, knee aspiration or injection of intra- articular steroid or hyaluronic acid since $\leq 3$ months were excluded from the study. Our research was approved by the Ethics Committee of our Medical Faculty Institute. All participants (OA patients and healthy subjects) gave informed written consent prior to participation in this study.

Patients were subjected to history taking, thorough clinical examination focusing on knee joint examination. Patients were asked to complete the Western Ontario and McMaster Universities Arthritis Index (WOMAC) osteoarthritis index questionnaire which is a multidimensional selfadministered questionnaire used to assess stiffness, physical function and pain. The WOMAC sub-scores are stiffness (0-8), pain (0-20) and incapacity (0-68). By adding these scores, the final number will range 
from 0 to $96 \quad(0$ score denotes the greatest health condition while 96 is the worst). The WOMAC score magnitude varies from 0 to 4 as none, mild, moderate, serious or extreme [16].

\section{Musculoskeletal ultrasound (MSUS) examination:}

Gray scale US imaging was applied using a Logiq 9 apparatus with a linear multi-frequency probe (M12 L) of $\mathrm{MHz}$ and a field of view of $40 \mathrm{~mm}$. Pulse repetition frequency was $700 \mathrm{~Hz}$ and color Doppler frequency 6.7 MHz.

Patients were asked to lie in a supine position. The knee joint was scanned in medial, lateral longitudinal scans as well as supra-patellar and infra-patellar transverse scans. The knee is put in 30 degree flexion for lateral and ventral scans, and put extended for dorsal scans as stated by the EULAR guidelines and the OMERACT guidelines $\quad[17, \quad 18]$ Synovial hypertrophy was considered if its thickness was >4 mm [19]. Synovial effusion was also measured in $\mathrm{mm}$ and considered absent if $<4 \mathrm{ml}$ [20]. The Baker's cyst diameter was taken in the transverse view and was considered inflamed if $10 \mathrm{~mm}$ and absent not inflamed if $<4 \mathrm{~mm}$ [21].

Osteophytes were considered if they appeared in the both longitudinal and transverse planes [21].

To estimate knee cartilage thickness, measurement should be taken on the medial and lateral femoral condyles and in the notch, while the knee is in full flexion. Cartilage thickness was deliberated from the thin hyper-echoic line at the soft tissue-cartilage line to the hyper-echoic line at the cartilagebone interface. Here, the probe should be located transversely to the leg and perpendicular to the bone surface, above the superior patellar brim [22].

Color Doppler ultrasound activity score was defined as follows:

- Grade $0=$ no intra-synovial color signal, grade $1=$ up to 3 single color signals or 2 single color signals and one confluent color signal representing only a low flow,

- Grade $2>$ grade one with $\leq 50 \%$ of the intra-articular zone filled with color signals demonstrating a clear flow, and

- Grade $3=>50 \%[23]$. 


\section{Laboratory Investigations:}

The mean serum VEGF level was measured by Enzyme Linked Immunosorbent Assay (ELISA) using polyclonal antibody which was directed against isoform 165 using the Rebio® Human VEGF EIA kit (Ray Biotech, Inc., Norcross, GA, USA) in line with the company's instructions, 3$4 \mathrm{~mL}$ venous blood samples were collected into biochemistry tubes then centrifuged at $+4^{\circ} \mathrm{C}$ and $3000 \mathrm{rpm}$ for 5 minutes, and stored at $-70^{\circ} \mathrm{C}$.

\section{Statistical analysis:}

All statistical analyses were conducted using STATA/SE version 11.2 for Windows (STATA corporation, College Station Texas).
The collected data were listed in forms of mean \pm Standard Deviation (SD) and range for both frequency and quantitative data while the percentage was for qualitative data. The distribution of quantitative data was examined using the Shapiro-Wilk W test for normal data. The Fisher exact test, the Mann-Whitney and the Independent t-test, Kruskal Wallis test was used, and then the post-hock test was done to examine the significance of differences according to type of data. Spearman correlation coefficient (rho) test was used to examine the association between VEGF, cartilage thickness and studied parameters. Statistical significance was considered at $\mathrm{p}<0.05$.

\section{Results}

Table 1: Comparisons between the studied groups regarding demographic data

\begin{tabular}{|c|c|c|c|c|c|}
\hline & iables & $\begin{array}{c}\text { Cases } \\
(\text { no. }=\mathbf{3 0})\end{array}$ & $\begin{array}{l}\text { Controls } \\
(\text { no.=20) }\end{array}$ & Test & $\mathbf{P}$ \\
\hline \multirow{2}{*}{$\begin{array}{l}\text { Sex } \\
\text { No. }(\%)\end{array}$} & Female & $23(76.67 \%)$ & $15(75 \%)$ & \multirow[t]{2}{*}{ FET } & \multirow[t]{2}{*}{1.00} \\
\hline & Male & $7(23.33 \%)$ & $5(25 \%)$ & & \\
\hline \multicolumn{2}{|c|}{$\begin{array}{l}\text { Age (years) } \\
\text { Mean } \pm \mathrm{SD} ;(\text { range })\end{array}$} & $\begin{array}{c}39.6 \pm 12.45 \\
\quad(19-65)\end{array}$ & $\begin{array}{c}37.7 \pm 3.93 \\
(35-45)\end{array}$ & $\mathrm{MW}=1.74$ & 0.08 \\
\hline \multicolumn{2}{|c|}{$\begin{array}{l}\text { BMI }\left(\mathbf{k g} / \mathbf{m}^{\mathbf{2}}\right) \\
\text { Mean } \pm \text { SD; (range) }\end{array}$} & $\begin{array}{l}25.45 \pm 3.18 \\
\quad(19-33)\end{array}$ & $\begin{array}{c}24.65 \pm 3.74 \\
\quad(19-33)\end{array}$ & $\mathrm{t}=0.78$ & 0.44 \\
\hline
\end{tabular}

BMI; Body Mass Index, SD: Standard Deviation; P: Probability, FET: Fisher Exact Test; MW: Mann-Whitney test, t: independent t-test; Bold values are significant. 

Thirty patients with primary knee OA were included in the study. They were 23 females (76.67\%) and 7 males (23.33\%) with ages ranging from 19 to 65 years (mean \pm SD $39.6 \pm 12.45$ years). Twenty apparently healthy subjects, matched for age and sex to the patients were involved as controls. They were 15 females (75\%) and 5 males (25\%) with ages ranging from 35 to 45 years (mean \pm SD $37.7 \pm$ years). All demographic characteristics showed non-significant statistical differences among patients and control groups regarding age, sex and $\mathrm{BMI}(\mathrm{P}=0.44)$.

Correlation between VEGF, cartilage thickness with musculoskeletal ultrasonogrsphic findings and other estimated parameters are expressed in tables (2\&3).

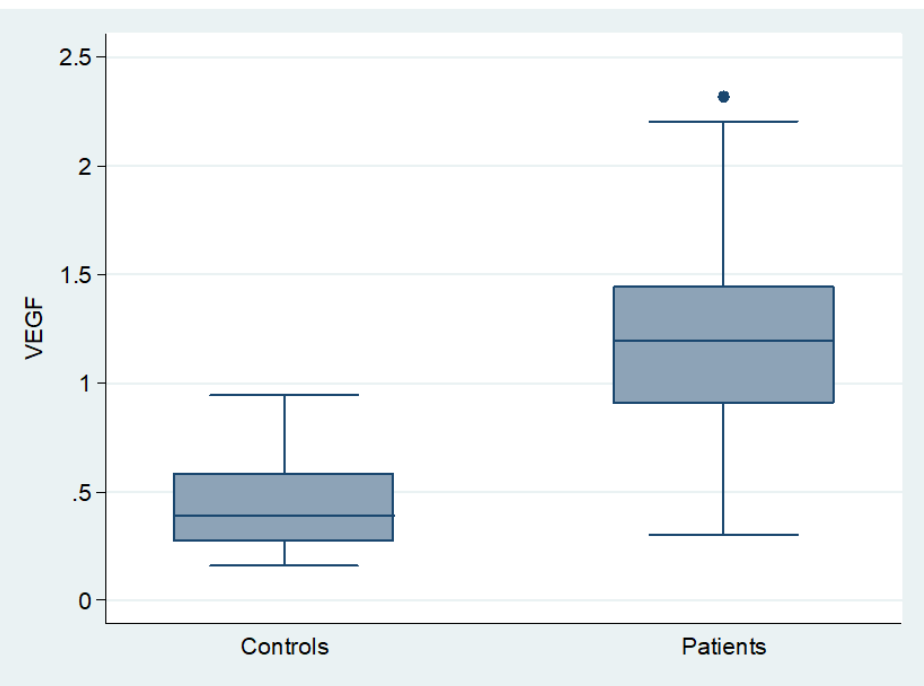

Fig (1): Shows comparison between patients and control groups as regards mean serum VEGF level with highly statistically significant differences of VEGF levels between the two groups ( $\mathrm{p}$-value $=0.001$ ).

Table (2): Correlation between VEGF, cartilage thickness and musculoskeletal findings in studied cases

\begin{tabular}{lcccc}
\hline $\begin{array}{l}\text { Variable } \\
\text { (no.=30) }\end{array}$ & Rho & VEGF & P & \multicolumn{2}{c}{$\begin{array}{c}\text { Cartilage thickness }(\mathbf{m m}) \\
\text { Rho }\end{array}$} & P \\
\hline Synovial effusion & -0.01 & 0.95 & -0.12 & 0.51 \\
Synovial hypertrophy & -0.28 & 0.15 & 0.33 & 0.08 \\
Osteophytes & -0.24 & 0.20 & 0.19 & 0.30 \\
Bursitis & 0.28 & 0.13 & -0.36 & 0.05 \\
Backer cyst & 0.31 & 0.10 & -0.42 & $\mathbf{0 . 0 2}$ \\
Doppler & 0.88 & $\mathbf{< . 0 0 1}$ & -0.93 & $<\mathbf{0 . 0 0 1}$ \\
\hline
\end{tabular}

Rho: Spearman correlation coefficient; Bold values are significant. 
Table (3): Correlation of VEGF and cartilage thickness with estimated parameters in studied cases

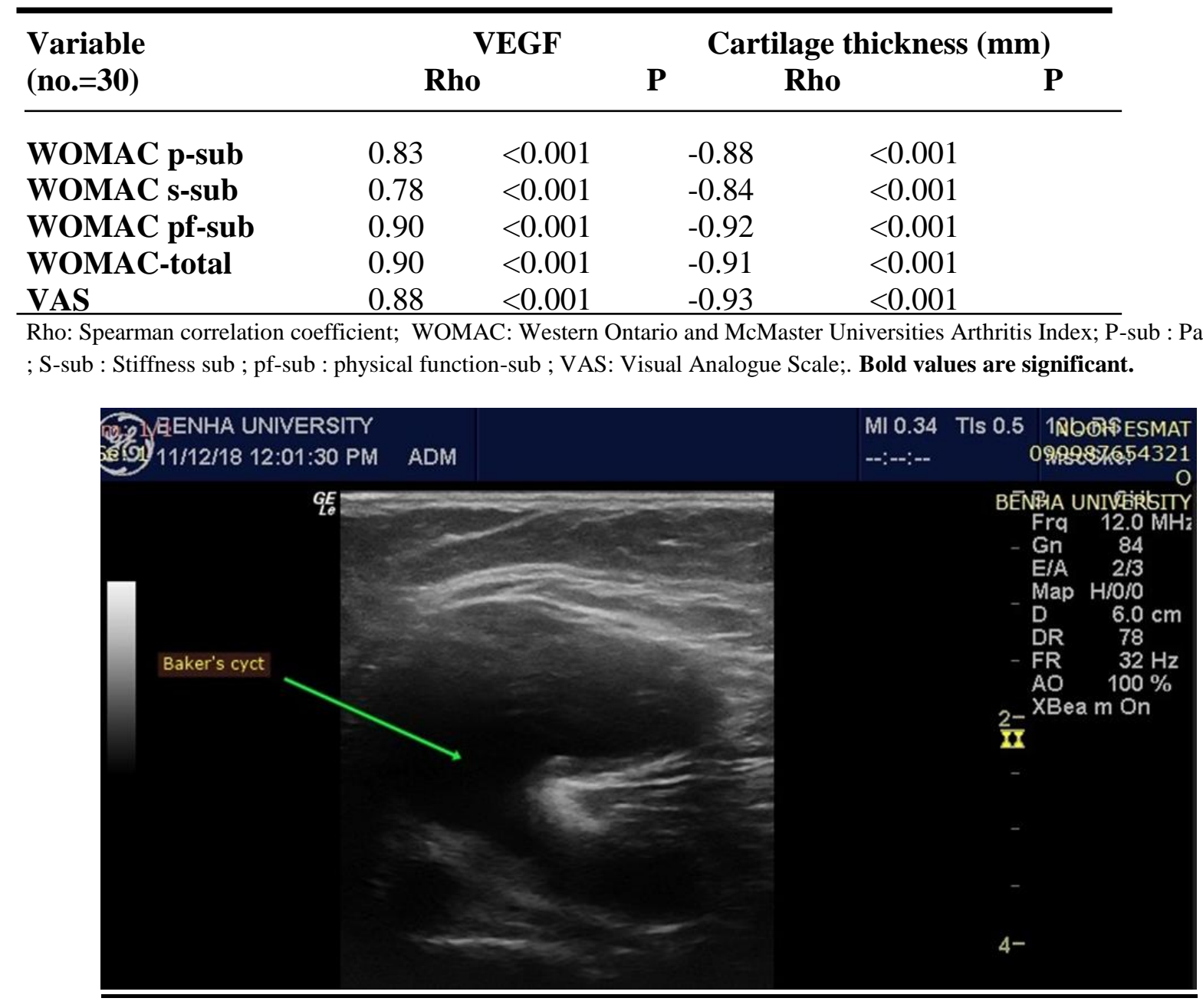

Fig (2): transverse view of post aspect of knee showing Baker's cyst. (WOMAC score 94 and s. VEGF 2.3175)

\section{Discussion}

VEGF plays an important role in inflammatory disorders like rheumatoid arthritis, Behcet's disease (BD) and systemic lupus erythematous that showed increased serum VEGF levels [24]. In this study there was a great of statistical significant difference as regards to VEGF levels between the study groups $(\mathrm{p}<0.001)$. In concord with our results Ballara et al. [25] found higher VEGF concentrations in inflammatory arthritis and OA in comparison to polyarthralgia and normal subjects. 
Moreover, in a study conducted by Fay et al. [26] there was an increased synovial fluid levels in OA joints more than healthy ones. On the contrary, Saetan et al. [27] established no significant difference in plasma VEGF level between patients with $\mathrm{OA}$ and control groups.

Additionally, in the current study VEGF levels significantly correlated with cartilage thickness, Baker cyst and Doppler US grading detected by US. This was comparable to the results of ElNajjar et al. [28] who revealed a significant association of synovial fluid and serum VEGF levels with KOA severity weighed by radiographic K-L scale, PDUS grading and with cartilage thickness in OA joints. We also found highly statistically significant correlations between VEGF levels and KOA severity scores for clinical manifestation $(\mathrm{p}<0 . ; \boldsymbol{r}=)$, VAS $(\mathrm{p}<0$. ; $\boldsymbol{r}=)$, early morning stiffness $(\mathrm{p}<0 . ; \boldsymbol{r}=$ ) ICOM $(\mathrm{p}<0 . ; r=)$ and WOMAC index $(\mathrm{p}<0 . ; \boldsymbol{r}=)$. Moreover, all these parameters highly statistically correlated with cartilage thickness values $(\mathrm{p}<0 . ; \quad r=)$ detected by ultrasonography. These finding were compliant with Saetan et al. [27] results who stated that synovial inflammation features detected by US are more common in painful KOA joints rather than in symptomatic or normal knees, while no significant association between pain and individual US features was found. In a similar track, an Egyptian study found that biomarker synovial fluid level has significant correlation with clinical manifestations, functional impact, as well as radiological changes [29].

Kim et al. [30] in their study concluded that synovial fluid VEGF levels well correlated with ultrasonographic findings and functional status of KOA.

Limitations of this study comprised the quite small contributors' numbers. So we recommend further studies with larger sample size better delineate the findings and understanding of the role of VEGF on the development and progression of osteoarthritis to help finding the therapeutic targets for prevention and treatment of OA

\section{Conclusion:}

Serum vascular endothelial growth factors highly correlated with clinical, functional and musculoskeletal ultrasound findings in knee $\mathrm{OA}$ 
patients. Thus VEGF might serve as a potential biomarker for estimating Knee OA disease status.

\section{Abbreviations:}

KOA: Knee osteoarthritis

WOMAC: Western Ontario McMaster Osteoarthritis index

\section{US: ultrasound}

\section{CDUS: Color Doppler US}

VEGF: Vascular endothelial growth factor

VEGFR2: Vascular endothelial growth factor receptor 2

\section{References:}

[1] M.B. Goldring . Berenbaum . Emerging targets in osteoarthritis therapy. Curr Opin Pharmacol. 2015;22:51-63. doi: 10.1016/j.coph.2015.03.004. [PMC free article] [PubMed] [CrossRef] [Google Scholar

[2]Y. Elsiwy, I. Jovanovic , K. Doma , K. Hazratwala , H. Letson : Risk factors associated with cardiac complication after total joint arthroplasty of the hip and knee: a systematic review. J Orthop Surg Res. 2019 Jan 11;14(1):15.

[3]. A.C. Bay-Jensen, C.S. Thudium, O. Gualillo and A. Mobasheri :Biochemical marker discovery, testing and evaluation for facilitating OA drug discovery and development Drug Discovery Today, (2017) 23 (2). pp. 349-358

[4].C.R. Scanzello , S. R. Goldring: The role of synovitis in osteoarthritis pathogenesis Aug;51(2):24957. doi:10.1016/j.bone.2012.02.012. Epub 2012

Feb 22.

[5] Y. Henrotin ,L. Pesesse , C. Lambert. Targeting synovial angiogenesis as a novel treatment approach to osteoarthritis Review article find in PubMed • February

2014 Therapeutic advances in musculoskeletal disease 6(1):20-34

DOI: $10.1177 / 1759720 \times 13514669$

[6] Lee, Y.H., Bae, S. Correlation between circulating VEGF levels and disease activity in rheumatoid arthritis: a meta-analysis. Z Rheumatol 77, 240-248 (2018). https://doi.org/10.1007/s00393-016-0229-5

[7].C. Lambert, M. M. Hartert, J.E. Dubuc, E. Montell, J. Vergés, C. Munaut, et al.,: Characterization of synovial angiogenesis in osteoarthritis patients and its modulation by chondroitin sulfate Arthritis Research \& Therapy volume 14, Article number: R58 (2012) Cite this article Research article Open Access Published: 12 March 2012

.[8].H. Kai and R. Bjorn . Olsen: Vascular Endothelial Growth Factor Control Mechanisms in Skeletal Growth and Repair Published online 2016 Dec 29. doi: $10.1002 /$ dvdy. 24463

.[9]. J.P .Tong, Y.F .Yao: Contribution of VEGF and PEDF to choroidal angiogenesis: a need for balanced expressions. Clin Biochem. 2006;39:267-276. [PubMed]Google Scholar[

[10]. K1.Park, H2. Amano, Y3. Ito, S4 .Kashiwagi, Y4. Yamazaki, A4.Takeda et al., Vascular endothelial growth factor receptor-1 (VEGFR-1) signaling enhances angiogenesis 
in a surgical sponge model. BiomedPharmacother. 2016; 78:140149.

[11]T. Saito, A. Fukai, A. Mabuchi, T. Ikeda, F. Yano, S. Ohba, et al., (2010): Transcriptional regulation of endochondral ossification by HIF-2alpha during skeletal growth and osteoarthritis development. Nat Med 16, 678-686.

[12] D.A. Walsh, L. Haywood Angiogenesis: a therapeutic target in arthritis CurrOpin Invest Drugs, 2 (2001), pp. 1054-1063

[13] D.A. Walsh, M. Wade, P.I. Mapp, D.R. Blake Focally regulated endothelial proliferation and cell death in human synovium Am J Pathol, 152 (1998), pp. 691-702 View Record in Scopus Google Scholar.

[14]F. Porta, G. Radunovic , V. Vlad, M.C. Micu, R.Nestorov,T. Petranova, et al., The role of Doppler ultrasound in rheumatic diseases. Rheumatology 2012; 51: 976e8

[15].R. Altman, E. Asch , D. Bloch Bole, K.D. Brandt, D.V. Cooke, Greenwald RA et al., Development of clinical criteria for osteoarthritis. J Rheumatol. 1987 May; 14(Spec No):3-6. [PubMed] [Google Scholar]

[16] N. Bellamy, J. Campbell, J. Hill, P. BandA comparative study of telephone versus onsite completion of the WOMAC 3.0 osteoarthritis index J Rheumatol, 29 (4) (2002), pp. 783-78

[17 ] .M. Backhaus, G.R. Burmester , T. Gerber , W. Grassi , K.P. Machold , W.A. Swen, et al. Guidelines for musculoskeletal ultrasound in rheumatology Ann Rheum Dis,
60 (2001), pp. 641-649 View Record in ScopusGoogle Scholar

[18 ] .R.J. Wakefield, P.V. Balint, M. Szkudlarek, E. Filippucci, M. Backhaus, M.A. D’Agostino, et al., Musculoskeletal ultrasound including definitions for ultrasonographic pathology J Rheumatol, 32 (2005), pp. 24852487 View Record in Scopus Google Scholar

[19] Wakefield RJ, Balint PV, Szkudlarek M, Filippucci E, Backhaus M , D 'Agostino MA, et al: Musculoskeletal ultrasound including definitions for ultrasonographic pathology. [erratum appears in J Rheumatol. 2006 Feb;33 (2):440 Note: Bruyn,George [corrected to Bruyn, George AW].

[20] M.A. D’Agostino, P. Conaghan, M. Le Bars, G. Baron, W. Grassi, E. Martin-Mola et al., EULAR report on the use of ultrasonography in painful knee osteoarthritis. Part 1: Prevalence of inflammation in osteoarthritis Ann Rheum Dis, 64 (2005), pp. 1703-1709 Cross RefView Record in Scopus Google Scholar.

[21]S. Gehan. Seifeldein, A. Haseib, A. Hosam, H., G. Ahmed. Correlation of knee ultrasonography and Western Ontario and McMaster University (WOMAC) osteoarthritis index in primary knee osteoarthritis Egyptian Journal of Radiology and Nuclear Medicine volume 50, Article number: 28 (2019).

[22] A.M. Aisen, W.J. McCune, A. MacGuire, P.L. Carson, T.M. Silver, S.Z. Jafri, et al. Sonographic evaluation of the cartilage of the knee Radiology, 153 (1984), pp. 781-784 
Cross RefView Record in Scopus Google Scholar.

[23]N. Beitinger, B. Ehrenstein, B. Schreiner,

M. Fleck, J. Grifka, C. Lüring,et al., :.The value of colour Doppler sonography of the knee joint: a useful tool to discriminate inflammatory from non-inflammatory disease? Rheumatology (Oxford), 52 (8) (2013), pp. 1425-1428. CrossRefView Record in Scopus Google scholar

[24] L .M.S. Rivera, L.V. Ríos, C.D.Hernández, C.P. Villaseñor .: Usefulness of measuring common carotid intima-media thickness: Ultrasound diagnosis of sub-clinical atherosclerosis in rheumatic diseases. A literature review* Revisión de la literatura. Rev Colomb Reumatol. 2016;23:92-101.

[25] S. Ballara, P.C. Taylor, P. Reusch, D. Marmé, M. Feldmann, R.N. Maini, et al. Raised serum vascular endothelial growth factor levels are associated with destructive change in inflammatory arthritis Arthritis Rheum, 44 (9) (2001), pp. 2055-2064 View Record in Scopus Google Scholar

[26] J. Fay, D. Varoga, J. Wruck, B. Kurz, M.B. Goldring, T. PufeReactive oxygen species induce expression of vascular endothelial growth factor in chondrocytes and human articular cartilage explants, Arthritis $\begin{array}{lllll}\text { Res Ther, } 8 \text { (6) (2006), p. R189 } & \text { (6) }\end{array}$ CrossRefGoogle Scholar.

[27]. N. Saetan, S. Honsawek ,A. Tanavalee, P. Yuktanandana ,S Meknavin, S Ngarmukos et al., : Relationship of plasma and synovial fluid vascular endothelial growth factor with radiographic severity in primary knee osteoarthritis Int Orthop, 38 (2014), pp. 10991104 Cross RefView Record in Scopus Google Scholar

[28] El-Najjar AR, Ezzeldin N, Khalil SS, ElGerby KM, Alazizi NM, Ibraheem HA. Vascular endothelial growth factor and colour doppler ultrasonography in knee osteoarthritis: Relation to pain and physical function. The Egyptian Rheumatologist. $2019 \quad$ Apr $1 ; 41(2): 139-43$.

[29] A. Gaballah, N.A. Hussein, M. Risk, N. Elsawy , S. Elabasiry. Correlation between synovial vascular endothelial growth factor, clinical, functional and radiological manifestations in knee osteoarthritis Egypt Rheumatol, 38 (1) (2016), pp. 29-34 Article Download PDF View Record in Scopus Google Scholar

[30] H.R. Kim, J.H. Lee, K.W. Kim, B.M. Kim, S.H. Lee: the relationship between synovial fluid VEGF and serum leptin with ultrasonographic findings in knee osteoarthritis Int J Rheum Dis, 19 (2016), pp. 233-240.

To cite this article: Mayada Khalil, Mounir Serag Eldeen, Samy E. Egela, Yasmine Hadhoud, AlShaimaa M. Al Tabbakh. Correlation between Vascular Endothelial Cell Growth Factor (VEGF) and Muscular Ultrasonography Finding in Knee Osteoarthritis. BMFJ 2021;38(1): 102-112. DOI: 10.21608/bmfj.2020.48028.1334 